\title{
Research the Length of the Braking Distance for Speed and High- Speed Trains on Railway Sections
}

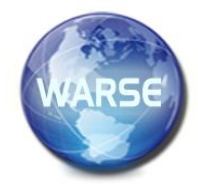

\author{
Ravshan Aliev', Marat Aliev², Ezozbek Tokhirov ${ }^{3}$, Kamoliddin Tashmetov ${ }^{4}$ \\ ${ }^{1}$ Tashkent State Transport University, Tashkent, Uzbekistan, silara@mail.ru \\ ${ }^{2}$ Tashkent State Transport University, Tashkent, Uzbekistan \\ ${ }^{3}$ Tashkent State Transport University, Tashkent, Uzbekistan, etokhirov@yahoo.com \\ ${ }^{4}$ Tashkent State Transport University, Tashkent, Uzbekistan
}

\begin{abstract}
The article provides a methodology for calculating the length of the braking distance on high-and high-speed sections of the railway of «UzbekistonTemirYollari» JSC.Method for calculating the lengthduring emergency braking.According to the developed methodology, it is possible to determine information about the state of the input traffic light on a locomotive at a distance sufficient for emergency braking and, based on these calculations, develop technical measures to ensure unhindered train movement. The indication ahead of the traffic light in front of the vehicle is repeated in the cab of a locomotive driver when the train travels between two traffic lights or over a section of a given length near the floor signal.Information displayed about the permitted speed, taking into account all restrictions. It is also possible to display information about upcoming restrictions, braking distance, speed, etc. Based on static speed information, the on-board unit and floor unit calculate the braking speed curve. The system continuously displays the maximum permissible speed in the driver's cab, which is consistent with the following limit and therefore cannot be exceeded at the moment. This requires information about the distance to the next restriction. This information may be transmitted individually for a block section or standardized using a block section of a certain length. Unification of the length of block sections is justified only in case of predominantly homogeneous traffic, e.g. on specialized high-speed sections or suburban lines. The above expressions are used to analyze the automatic locomotive alarm system and determine the required length of the rail line. The optimum length of the rail coding line is determined and, based on the above expressions, an algorithm can be developed and programs can be drawn up taking into account the length of the braking distance
\end{abstract}

Keywords:braking distances, average unit braking force, locomotive slowdown, slowdown train

\section{INTRODUCTION}

In JSC "UzbekistonTemirYollari" on speed and high-speed sections of the railway equipped and not equipped with automatic blocking devices, for ensure the safety of train traffic with the use of traffic lights and without the use of traffic lights, use automatic locomotive signaling systems [12].
Currently in the systems of interval regulation of train traffic for improve the safety of train traffic, track devices of interval regulation are necessarily supplemented by automatic locomotive signaling systems, and in some cases they switch to regulation of train traffic without floor traffic lights, locomotive systems are becoming the main systems for regulating train traffic.

In a number of foreign countries: France, Germany, Spain, Italy, Sweden, the United States of America, etc. [1], [4], [5],[6], [7],[8], to increase the safety of train traffic on high-speed lines, train control systems have been developed and are being developed, such as the TVM $300 / 430$, in which signal information is transmitted to the locomotive over the rail channel using frequency modulated signals, as well as through thelaid along the rails plumes LZB - 80, 500, 700, 702.

\section{METHODS}

Since on the Uzbek railway it is envisaged to monitor the freedom of the haul using axle counters, then at the train approaches the station, a prerequisite is the transmission of information to the locomotive about the state of the input traffic light at a distance sufficient for emergency braking in the event of a closed state of the input traffic light. This distance can be determined by the following expression:

where:

$$
L_{l}=L_{k}+L_{a}+L_{b}
$$

$L_{\mathrm{K}}$ isthe distance traveled by the train from the moment the code signal is received by the automatic locomotive signaling devices;

$L_{a}$ isbefore the brake system of the train is activated;

$L_{b}$ isbraking distance of the train from the beginning of braking.

The most common in practical use is the analytical method for calculating the stopping distance, based on the numerical integration of the train motion equation $[2 ; 3]$ by speed intervals. By this case, the braking distance $L_{b}$ in the calculations is taken to be equal to the sum of the preparatory path $L_{p}$ (pre-brake), triggering of threshold elements $L_{t e}$ and valid path $L_{v}$ of braking:

$$
L_{t}=L_{p}+L_{v}+L_{t e}
$$

The division of the braking distance into $L_{p}$ and $L_{a}$ is purely conditional and is taken to simplify calculations in 
the area of a transient mode of action of the braking force. Is accepted that during the time the train travels the prebraking distance, the brakes in action haven't come yet, and by the end of the pre-braking distance, there is an instantaneous increase in the braking force to the maximum value, i.e., the braking force of the train does not increase gradually, and instantly, later some time, called preparation time.Such conditions correspond to the assumption, that filling the brake cylinders with air on the train occurs not by valid for each railway carriage, and after some time $t_{p}$ called preparation time in all railway carriage simultaneously [8].

In expression (2) $\mathrm{L}_{p}$ isway, passable by train per the time preparation of brakes for action, $\mathrm{m}$ :

$$
L_{p}=V_{p} \cdot t_{p},
$$

where $t_{p}$ is time to prepare the brakes for action;

$$
t_{p}=20-\frac{200_{i}}{b_{T}}
$$

$i$ is slope of the path, $i=-3 \%$;

$b_{T}$ isaverage specific braking force, $\mathrm{N} / \mathrm{t}$;

$$
b_{T}=15000 \vartheta_{p_{n c m}} \varphi_{\text {кр }} \text {. }
$$

$L_{a}$ isactual braking way, traversed by the train at maximum pressure in the brake cylinder;

$$
L_{a}=\frac{\xi^{-1}}{2} \sum_{1}^{n} \frac{V_{n+1}^{2}-V_{n}^{2}-V_{n-1}^{2}}{b_{T}+w_{0}+b_{i}},
$$

$V_{n+1}, V_{n}, V_{n-1}$ are initial and final speed in the accepted design interval, $\mathrm{m} / \mathrm{s}$;

$b_{i}=10 * i$ is specific resistance to train movement from the slope of the track, N/t;

$w_{o}$ is main specific resistance to train movement, $\mathrm{N} / \mathrm{t}$;

$Q_{j}$ is part of the train mass attributable to wagons of a given type and downloads;

$\xi$ istrain deceleration, $\mathrm{m} / \mathrm{s}$, under the influence of a retarding force of $1 \mathrm{~N} / \mathrm{t}$;

$$
\xi=\frac{\xi_{L} \bar{Q}_{L}+\xi_{T} Q_{T}}{\bar{Q}_{L}+Q_{T}},
$$

$\xi_{L}$ islocomotive deceleration, $\mathrm{m} / \mathrm{s}$

$\xi_{T}$ isdeceleration of the train, $\mathrm{m} / \mathrm{s}$

$\bar{Q}_{L}$ isaccounting mass of the locomotive, $t$ [9]

$\mathrm{Q}_{\mathrm{T}}$ istrain mass, $\mathrm{t}$

$$
\begin{gathered}
w_{o}=\frac{w_{o}^{I} \bar{Q}_{L} \sum w_{o j}^{I I} Q_{j}}{\bar{Q}_{L} \sum Q_{j}}, \\
w_{o}^{I}=24+0.396 V_{a}+0.045 V_{a}^{2}
\end{gathered}
$$

$w_{o}^{I}$ ismain specific resistance to movement of the locomotive, $\mathrm{N} / \mathrm{t}$

$V_{a}=V_{n}+V_{n+1} / 2$ isaverage train speed in the selected interval, $\mathrm{m} / \mathrm{s}$;

$w_{o j}^{I I}$ ismain specific resistance to the movement of cars of this type, taking into account their actual load, $\mathrm{N} / \mathrm{t}$;

$$
w_{o j}^{I I}=7+\frac{30+3.6 V_{\mathrm{cp}}+0,324 V_{\mathrm{cp}}^{2}}{\mathrm{q}_{o}},
$$

$\mathrm{q}_{o}$ isaxial load, $\mathrm{t}$;

$L_{d}$ is the distance traveled by the train after changing the signal indication on the locomotive devices.

If we take into account the cycle time of the code signal $t_{p}=1,7 \mathrm{sec}$.and the transition from one signal indication to another then during this time the train will cover the distance:

$$
L_{d}=V_{\Pi} \cdot t_{p} \cdot 3
$$

\section{RESULTAND DISCUSSIONS}

With considering into account the above, the length of the section of the approximations to the input traffic light and to the intersection of road and rail transport with considering into account the reliable braking and stopping of the train near of the input traffic light and near the level crossing is determined based on the presented mathematical expressions.

Algorithm developed and program compiled, which can be used for alert the locomotive driver and person on duty by station about the approach speed. Infigure 1 proposed oneoftheblockdiagramsand in figure 2 research of the length of the braking distance for speed and high-speed trains.

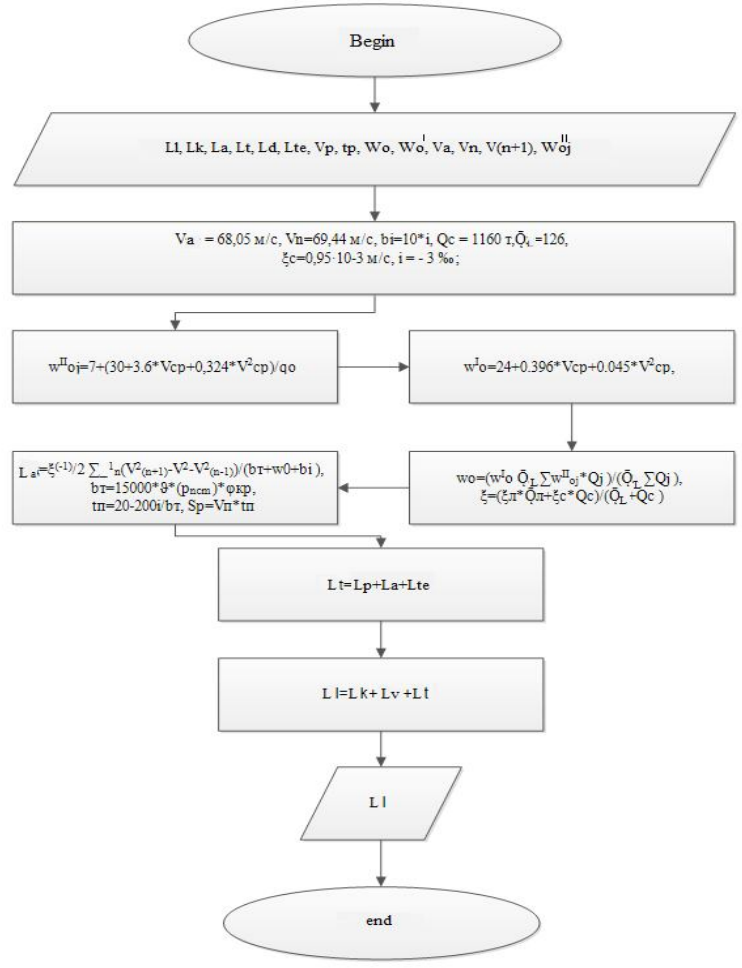

Figure 1:Block-scheme

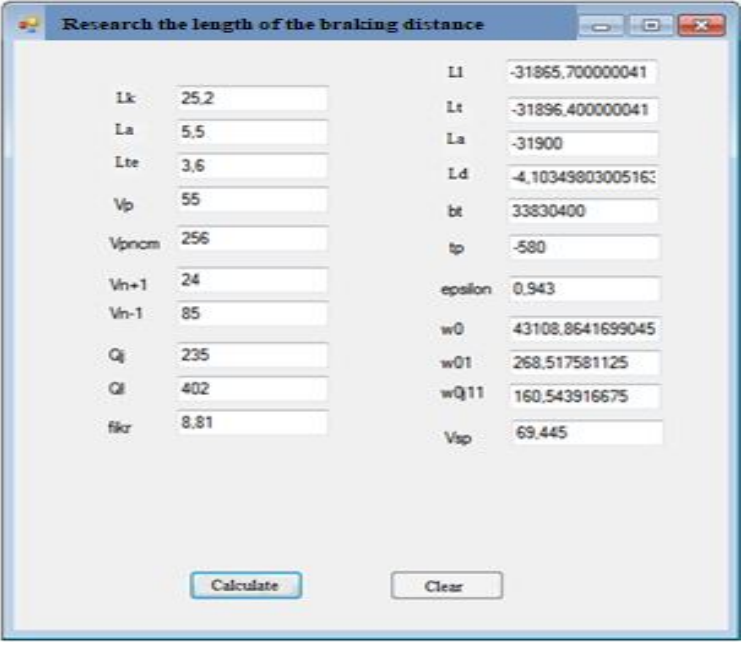

Figure 2:General view of the calculation using a computer program 
The time it takes for the train to brake completely at the initial speed $\mathrm{Vn}$, can be determined by the formula:

$$
t=t_{p}+\sum_{1}^{n} \Delta t_{V}=t_{p}+t_{V}
$$

where $t_{p}$ istime to prepare the brakes for action

$\Delta t_{V}$ isvalid braking time;

$$
\Delta t_{V}=\frac{\Delta L_{a}}{V_{a}} .
$$

$\Delta L_{a}$ isactual braking way.

The quantity average deceleration is determined by the formula:

$$
j=\frac{V_{n}-V_{n+1}}{\Delta t_{V}}
$$

\section{CONCLUSION}

Based on all of the above, it is necessary to conduct research and determine the optimal section length of the approach, at which, under the locomotive's take-up coils be provided of the normative current of actuation of the devices automatic locomotive signaling.

\section{REFERENCES}

1. Further increase in speedtrain movements onJR East:[tasks, prospects of the railway. JR East (Japan), serving the Shinkansen high-speed communications network] //Railways of the world No.10,PP. 46-50, 2009

2. W.Vantuono. Control systems trains in USA. International RailwayJournal No.10,PP. 32-34,36, 2009

3. Dr.Sajed K Abed European Rail Trafic Management System- An Overview.Iraq J.Electrical and Electronic Engineering. Vol .6 No.2. PP. 172 - 179.

4. High-speed railway lines in the world: [overview information on foreign roads of Japan, Europe, etc.] // Railways: present and future No.3,PP. 167-180, 2007

5. Review of existing, under construction and planned high-speed lines in the world // World Railways No.12,PP. 9-15, 2007

6. Project of a high-speed transportation system for California// Railways of the world. No.10, PP. 4447, 2008

7. Development of high-speed traffic in Germany // Railways of the world.No. 4. PP. 21-25, 2009

8. Gregor Theeg, Sergej Vlasenko. Railway Signalling \& Interlocking. International Compendium.A DVV Media Group publication. Eurailpress, 2009, 448 p.

9. Asadchenko V.R. Automatic brakes of rolling stock: textbook for universities. etc. transport. - M.: Marshrut, 2006, 392 p.

10. Zorin V.I. Microprocessor-based locomotive systems for ensuring the safety of train traffic of a new generation / V. I. Zorin, E. E. Shukhina, P. V.Titov // Railways of the worldNo7.PP. $61-69$, 2003
11. ERTMS, Subset-036. FFFIS for Eurobalise. Access mode:http://www.era.europa.eu/DocumentRegister/Documents/Set-2-Index009-SUBSET-036 \%20v300.pdf.

12. Instructions for the movement of trains and shunting work on the railways of the Republic of Uzbekistan. - T.: Temiryulchi, 2009, 294p.

13. Intelligent transport systems of railway transport (fundamentals of innovative technologies) [Text]: manual / V. V. Skalozub, V. P. Soloviev, I. V. Zhukovitsky, K. V. Goncharov. - D .: Publishing house of Dnepropetr. nat. un-that railway - d. transport them. acad. V. Lazaryan, 2013, 207 p.

14. The concept of improving traffic safety based on the use of multifunctional integrated systems for regulating train traffic on the railways. "Russian Railways", 2006, 129 p.

15. Lisenkov V.M., Bestemyanov P.F., Leushin V.B. et al. Train traffic control systems on the tracks. Part 1; ed. Lisenkov V.M. - M .: GOU "Educationalmethodical center for education on the railway. trthose". Transport book, 2009, $160 \mathrm{p}$.

16. Eliminating the passage of a red light traffic light: new equipment and technology / EN Rosenberg [et al.] // Automation, communications, informatics: Popular scientific production and technical journal No.2,PP. 10-11, 2009.

17. R.M. Aliyev, M.M. Aliyev. Intelligent system of control of track circuits on high - speed lines. WCIS - 2016. 9 World Conference on Intelligent Systems for Industrial Automation. Tashkent, Uzbekistan, October, 2016.PP. 25-27.

18. Aripov, N. \& Aliyev, R. \& Baratov, D. \& Ametova, E. Features of Construction of Systems of Railway Automatics and Telemechanics at the Organization of High-Speed Traffic in the Republic of UzbekistanProcedia Engineering 134(2016) pp. 175180. DOI: $10.1016 /$ j.proeng.2016.01.057 